\title{
Supply Chain Operational Capability Affecting Business Performance of Creative Industries
}

\author{
Suryadi Hadi, Benyamin Parubak \\ Program Studi Manajemen \\ Universitas Tadulako \\ Palu, Indonesia \\ suryadihadi@untad.ac.id
}

\begin{abstract}
The creative industries can be used as a potential sector in order to reduce social problems and contribute to improve economy. The sustainability of this industry operation can be overcome by increasing the supply chain operational capability, such as, structural capabilities, logistics and technology. The purpose of this study is to collect detailed information on the implementation of supply chain operational capability in the creative industries and the extent of its effect on their performance. This research is categorized as descriptive and quantitative study through observation, documentation and literature review. This study also used an interview and delivered questionnaires to collect data through 155 respondents. The focus area of the creative industries in this study is printing businesses and crafts. Multiple regressions with SPSS Software tools was used to analyze the primary. Based on the results of this study, structural capability, logistics and technology have simultaneously affected to the performance of the creative industries. However, the technological capability partially has negative impact on the performance of the creative industries. Subsequent research in the area of this study is needed by using other research methods with the aim to enrich the concepts related to supply chain management.
\end{abstract}

Keywords-creative industries; supply chain operational capability

\section{INTRODUCTION}

Indonesia has rich of socio-cultural diversity as the capital to enhance creative industries. In addition, Indonesia has large of population which could support the sustainability of creative industries. Furthermore, the central government is also focus on strengthening this sector as source of income. Most of creative industries are categorized as small businesses so that they might have low capability to improve their business. Therefore, they must to adopt several strategies to enhance their performance. Supply chain management is one of several solutions for creative industries to survive in the competition.

The application of supply chain can help the creative industries to grow and develop. Then, they will have high competitive advantage. Supply chain management will enable the creative industries to manage their relationship with suppliers and customers so that the potential risk might be reduced. The harmonization between all elements involved in the supply chain could help the creative industries to improve profitability and efficiency in operations. Thus, cooperation should be increased and competition between each element in the supply chain can be avoided. Furthermore, previous literature review shows that there are less studies discussed about supply chain management in creative industry. In fact, most of literatures are focused on SMEs in general so that this paper is purposed to focus on creative industries with the aim to find new insight on applying supply chain in creative industries.

Capability has correlation to improve supply chain performance [1]. Capability include skills, resources, and other competencies can be used to help business in overcome rapid change environment [1], [2]. Most studies show that supply chain management have huge impact on the business performance. Thus, the role of supply chain management on increasing business performance is obvious. However, there are less studies that specifically examined the supply chain in the creative industries. Most of studies were carried out in USA and Europe compare to Asia and ASEAN countries. Most of the studies are focused on SMEs in general. Therefore, this study will conduct research focus on the creative industries in Indonesia, especially in Central Sulawesi Province. The main problem in this study consisted of: 1) how is the implementation of supply chain in the creative industries in Central Sulawesi Province; 2) how the relationship between supply chain operational capability and the performance of the creative industries in Central Sulawesi Province. Furthermore, the purpose of the implementation of this study is to collect detailed information on the implementation of supply chain and the constraints faced and examined further by the data empirically the theory study relating to the operational capabilities of the supply chain and its impact on the performance of the creative industries in Central Sulawesi Province.

\section{LITERATURE REVIEW}

\section{A. Creative Industries in Indonesia}

Creative industries are the backbone of Indonesian economy. Creative industries sector is expected to generate and sustain Indonesian economic growth [3]. Creative industries are one of vital sector for reducing the gap between 
the region by encouraging the competitive of region. It is expected that Indonesian productive population in 2030 will reach $67 \%$ with the average age 16-30 year of age. The proportion of Information technology access in Indonesia increase by 90 percent of population. The level of income of Indonesian people is also expected to increase by more than US\$3.600. Furthermore, Indonesia has international heritage culture and natural beauty which can be used as resource of creative industries.

According to reference [3], creative economy is any economic activities based on creativity, skills, individual talents to produce creativity and copyright which contain values and have influence to people. As in [3], creative industries include architecture, interior design, visual communication design, product design, fashion, film, video and animation, photography, skill, culinary, music, game and application, publishing, advertising, show exhibition, art, television and radio.

According to reference [4], Indonesia position is 115 compare to other ASEAN countries. The GCI index of Singapore was 0.896 while Indonesia was 0.202 . The GCI is measured three aspects include technology, talent and tolerance. Indonesia creative industries have lack of industrial development and financial [3]. Indonesia government had target that creative industries will create 13 million job opportunities and therefore local and global market will be expended. In addition, process and value chain facilities will also be provided. The most issue in developing craft business is human resources, while the issues in publishing business are financing and institutional [5].

\section{B. Supply Chain Operational Capability}

Internal structure support organization to enhance performance. Internal structure includes roles and relationship in organization [2]. Several positions in organization are control by internal structure with the aim to improve performance. Internal structure is one of the vital function in business organization include creative industries. Meanwhile, the roles of external structure are managing the relationship with other entities which have connected to the business organization [24]. The successful of managing this structure is depended by high personal skills of people in business organization. Thus, the people should have training and education in order to improve their professional skills to finish the tasks. Reference [6] suggest that the manager should also have high skills and knowledge to manage the internal in organization and external organization or partners.

Logistics function is a part of business organization and have strong relationship with other functional areas to improve performance. There are several studies claim that logistical capability connects to marketing, finance and operations to enhance the performance [7], [8]. The growth of 3PL in Indonesia increase significantly while the quality of service needs more improvement. But, the service quality of the 3PL is promising as the government has reformed several traditional policies to improve Indonesian logistics performance index in ASEAN as well as the global context.
The high activities of 3PL will provide an opportunity for creative industries to extend the ASEAN and global market. The 3PL will support the integration between distribution channel so that the product of creative industries will have smooth delivery process to reach the end customers [9], [10], [11]. The are several research claim that the better performance of 3PL will benefits SMEs in terms of cost and time delivery [12]. This will lead to enhance the customer service. Therefore, the logistical capability has strong relationship to enhance the business performance of creative industries.

There are many studies claim that technological capability is an important part to enhance business performance. Technology may help the company to reduce costs [1]. For example, information technology may be used to enable the company to share information via online and avoid to use paper base. IT can also be used to enhance service for customizing the customers. However, the application of technology can also have obstacles and depend on the type and size of the company [9]. IT is not easy to operate because of complexity, large investment, failure in outsource and lack of technological knowledge [9]. Most of Indonesian creative industries have not applied technology in their operations. Thus, it is also the critical challenge to prioritize these industries in the global market. In fact, small firm should have capability to enhance their technology in order to success in the competition with larger firm [13]. In this case, the role of government and other stakeholders play an important role.

\section{Business Performance of Creative Industries}

There are many studies have different point of view to define business performance. Some of literatures claim that business performance should be based on profit, ROI, and turn of number of customers [14]. However, the financial performance may difficult to be measured by ROI. For this reason, any change in operations will have an impact on ROI and lead to reduce performance [15]. Reference [16] found that the cash flow has a relationship to improve the performance of creative industries. Furthermore, some scholars claim that business performance can also be measured by their profitability, market share and sales growth [17]. Meanwhile, as in [18] stated that design quality and product improvement are the important indicator to measure business performance.

The literature review shows that the independent variables have significant impact on the business performance of creative industries. Therefore, a preliminary model is developed to analyze the relationship between the independents and dependents variables. As is illustrated on the literature review, the hypotheses are formulated as follow:

H1: The greater the structural capability, the better business performance of creative industries.

H2: The greater the logistical capability, the better business performance of creative industries.

H3: The greater the technological capability, the better business performance of creative industries. 
The relationship between the independent and dependent variables can be seen on Fig. I. The model is adapted by a previous study on the impact of supply chain operational capabilities on business performance of SMEs in Malaysia [19]. The reason for this, this study is intent to test the model in other type of business, size and country.

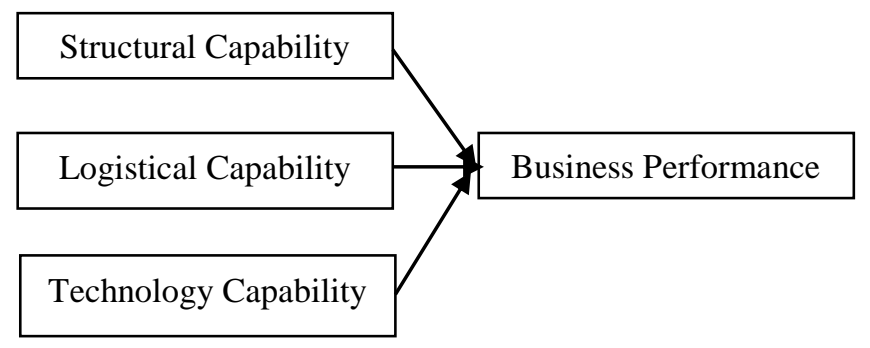

Fig. 1. Conceptual Model of Study

\section{RESEARCH METHODOLOGY}

TABLE I. VARIABLES AND INDICATORS USED IN THIS STUDY

\begin{tabular}{|l|l|}
\hline \multicolumn{1}{|c|}{ Variables } & \multicolumn{1}{|c|}{ Indicators } \\
\hline Ctructural & Formality works \\
& Intensive training for workers \\
& Intensive training for managers \\
& The ability of the staff in terms of IT \\
& Giving a role to the staff \\
& Relations between departments \\
& Intensive supervision \\
& The role of leadership \\
\hline Logistics & Logistics infrastructure \\
Capability (X2) & Business location \\
& The process of delivery of raw materials \\
& The process of delivery of products / services \\
& Distribution \\
& The scope of local distribution \\
& Distribution through outlets \\
& The scope of global distribution \\
\hline Technological & Application of advanced technologies \\
Capability (X3) & Network information \\
& Operational efficiency \\
& Information sharing to suppliers \\
& Information sharing to customers \\
& The level of product defects \\
& Production capacity \\
& Just in time strategy \\
& Cooperation with other parties \\
\hline Business & Growth in market share \\
Performance (Y) & Level of sales \\
& Supplier performance \\
& Inventories of raw materials \\
& Waiting time \\
& Quality of products / services \\
& Estimating performance \\
& Improve the ability of staff \\
& Improving internal communication \\
& Reducing customer complaints \\
\hline & \\
\hline
\end{tabular}

A survey is selected as the research design to identify the relationship between the constructs. The survey is suitable to collect data, minimize funding and generalize the findings. The object of this study is certain type of creative industries which are operating in Central Sulawesi Province in Indonesia. The primary data were collected through questionnaires and interview. Meanwhile, the secondary data were obtained by the Department of Tourism and Culture of Central Sulawesi Province in the period 2011-2013. There are 155 respondents involved in this study. The respondents involve in publishing and crafts businesses. These types of creative industries are chosen because this sector has strong contribution to be developed and help local and central government to reduce social and economic development issues. Multiple regression analysis is used to identify the relationship between the independents and dependent variables. The independent variable includes structural $\left(\mathrm{X}_{1}\right)$, logistics $\left(\mathrm{X}_{2}\right)$ and technological $\left(\mathrm{X}_{3}\right)$ capabilities. Meanwhile, the dependent variable is the business performance of creative industries (Y). Indicator of variables can be seen on the Tab. I. This study adapted 5-item Likert type scale. This study delivered questionnaires which are based on the literature review. Each of questionnaires was focused on one key respondent. Most of managers or owners are the target respondents in this study. Then, the data were analyzed by SPSS software. The following Table.I presents the variables and indicators which have been analyzed in this study.

\section{RESULTS AND DISCUSSION}

\section{A. Results}

A five-point Likert scale is applied to measure the independent variables. Reliability and validity test were undertaken to test each of independent variables. Cronbach's alpha is applied to check the reliability of each dimension. This study used a minimum Cronbach's alpha value of 0.60 and total correlations above 0.30 [19]. All construct in this study have a reliability value of more than 0.60 .

The multiple regression analysis on the Tab. II shows that the business performance of creative industries $(p<0.05)$ is positive significant impacted by structural capability. It confirms that human capital (H1) contributes to support the creative industries. In addition, the multiple regression analysis confirm that logistics capability would lead to support the business performance of creative industries. It is found that technological capability is statistically significant and positively associated with business performance $(\mathrm{p}<0.05)$ of creative industries in Indonesia.

TABLE II. MULTIPLE REGRESSION ANALYSIS

\begin{tabular}{|l|l|c|c|}
\hline \multicolumn{1}{|c|}{ Variables } & $\begin{array}{c}\text { Standardiz } \\
\text { ed Beta }\end{array}$ & t & Sig. \\
\hline Structural Capability (X1) & 0.682 & 13.165 & 0.000 \\
\hline Logistics Capability (X2) & 0.648 & 9.459 & 0.000 \\
\hline Technological Capability (X3) & 0.017 & 0.340 & 0.734 \\
\hline R2 & 0.813 & \\
\hline
\end{tabular}

Meanwhile, the result of the analysis describe that the analysis is insufficient to support the $\mathrm{H} 3(\mathrm{p}>0.05)$. Therefore, it cannot be said that greater technological capability will lead to generate better business performance of creative business in Indonesia. Thus, all dependent variables in this study, such as, structural, logistical, and technological have strong 
relationship with business performance of creative industries is high $(\mathrm{R}$-squared $=0.813)$. Table. II summarize the results of multiple regression

\section{B. Discussions}

Structural capability has significantly impact on the business performance of the creative industries. the results show that training for employees and managers have positive correlation to the business performance of creative industries. The result of this study is similar to previous study that structural capability has positive impact on the business performance [20], [21]. There is a significant relationship between structural capability and business performance of creative industries. Therefore, the findings of this study has consistent result to the previous findings. Meanwhile, logistics capability is also one of variable that can affect the business performance of creative industries. High logistics capability may impact the business performance in terms of cost and quality. But, other study found that there is negative correlation between logistics capability and business performance of SMEs [20]. Meanwhile, according to [22] logistics performance has significant impact on the financial performance of SMEs. The speed of delivering raw material into the focal company may contribute to transform raw material on time and delivering the final products to the customers. The final customers would easy to have the final product. Thus, the company could obtain competitive advantage. However, the global coverage is also a reason for creative industries to extent their market. In this case, the local and central government have significant role to help the creative industries due to lack of resources.

However, this study found that the technological capability has less impact on the business performance of creative industries. Most of respondents involved in this study have not shown a positive response. Most of the respondents involved in the craft business has not maximized the application of technology. Most of them believe that the conventional approach is more valuable because the work contains skills which based on culture. Therefore, the technological capability might less impact on the business performance. Furthermore, publishing industry has also similar issue to the craft industry but they also have not been updated their technology yet. Lack of resource and network connection are the most common problems that should be resolved. The result of this study is contrast to other studies on the relationship between technological capability and business performance [20], [23]. The previous study found that there is strong relationship between technological capability and business performance.

\section{CONCLUSION}

Implementation of supply chain operational capability has simultaneous impact on the business performance of the creative industries. The independent variables consist of structural capability, logistics capability and technological capability, while the dependent variable includes business performance of creative industries. Structural capability has significant impact on their business performance. In addition, logistics capability has positive impact on their business performance. However, technological capability has no significant impact on the business performance of creative industries in Central Sulawesi Province. Most of the respondents have not been utilized modern technology in their business operations. Some studies found that technology could help businesses to gain competitive advantages. They may produce high quality product and help them to run their operations efficiently. This study also found that lack of knowledge about the benefit of applying technology in their business operations is also the one of the critical issue. Lack of resources, such as, capital to invest technology and skills to operate technology are also impact their performance. In addition, the local government has less to provide assistant This study has limitation in terms of analytical tool so that further research in these industries is demanded. The findings can be used by the policy makers to form any master plan to develop this sector. The findings can also be used by other researchers to test all variables in different type of business in creative industries and regions or countries in order to generalize the findings.

\section{AKNOWLEDGEMENT}

This research is sponsored by HIBAH BERSAING DIKTI 2016

\section{REFERENCES}

[1] J. J. -K. Cho, J. Ozment, and H. Sink, "Logistics capability, logistics outsourcing and firm performance in an e-commerce market, "International Journal of Physical Distribution \& Logistics Management, 38(5): 336-359, 2008.Closs et al., 2008.

[2] L.M.Corbett and G. S. Claridge, "Key manufacturing capability elements and business performance" International Journal of Production Research, 40(1): 109-131, 2002.

[3] Hamdan, "Policy and Development Strategic of Creative Economy," Kebijakan dan Strategi Pembangunan Ekonomi Kreatif, unpublished, 2016.

[4] R. Florida, C. Mellander, K.M. King, "The Global Creativity Index,"Martin Prosperity Organization, 2015.

[5] R. B. Handfield, and B. Withers, "A comparison of logistics management in Hungary, China, Korea, and Japan," Journal of Business Logistics, 14(1): 81-109, 1993

[6] B. T. Kumagai, and B.H. Kleiner, "Managing the transition to supervision," Work study, 44(1): 8-10, 1995.

[7] E.A. Morash, C.L.M. Droge, and S.K. Vickery, "Strategic logistics capabilities for competitive advantage and firm success," Journal of Business Logistics, 17(1): 1-22, 1996.

[8] A. E. Ellinger, P. J. Daugherty, and S. B. Keller,'The relationship between marketing/logistics interdepartmental integration and performance in U.S. manufacturing firms: An empirical study. Journal of Business Logistics, 21(1): 1-22, 2000.

[9] L. E. Gill, and R.P. Allerheiligen, "Co-operation in channels of distribution: Physical distribution leads the way," International Journal of Physical Distribution \& Logistics Management, 26(5): 49-63, 1996.

[10] A.G. Waller, "Computer systems for distribution planning," International Journal of Physical Distribution \& Logistics Management, 25(4): 35-45, 1995. 
[11] J. Kallio, T. Saarinen, M. Tinnila, and A. P. J Vepsalainen, "Measuring delivery process performance," The International Journal of Logistics Management, 11(1): 75-87, 2000.

[12] M.S. Sohail, R. Bhatnagar, and A.S. Sohal, "A comparative study on the use of third party logistics services by Singaporean and Malaysian firms," International Journal of Physical Distribution \& Logistics Management, 36(9): 690-701, 2006.

[13] J. Kennedy, and P. Hyland, "A comparison of manufacturing technology adoption in SMEs and large companies. The 16th Annual Conference of Small Enterprise Association of Australia and New Zealand (pp. 1-10). Ballarat: University of Ballarat, 2003.

[14] E. H. Wood, "The internal predictors of business performance in small firms," Journal of Small Business and Enterprise Development, 13(3): 441-452, 2006.

[15] M. Simpson, J. Padmore,, N. Taylor, and J. Frecknall-Hughes, "Marketing in small and medium sized enterprises," International Journal of Entrepreneurial Behaviour \& Research, 12(6): 361-387, 2006.

[16] P. Benyamin, S. Hadi, "Analysis of Supply Chain Management in Indonesian Creative Industries," $1^{\text {st }}$ International Conference on Science, Technology, and Humanity, 2015.

[17] M. Feng, M. Terziovski, and D. Samson, "Relationship of ISO 9001:2000 quality system certification with operational and business performance: A survey in Australia and New Zealand-based manufacturing and service companies," Journal of Manufacturing Technology Management, 19(1): 22-37, 2008.

[18] B. F. Laura, K.V. Shawnee, and L.M.D Cornelia," The contribution of quality to business performance," International Journal of Operations \& Production Management, 16(8): 44-62, 1996.

[19] J. F. Pallant, "SPSS Survival Manual: A Step by Step Guide to Data Analysis using SPSS for Windows (Version 15). (3rd ed ed). Crows Nest, NSW: Allen \& Unwin, 2007.

[20] S. N. A. Zulkifli, "The Impact of Supply Chain Management on Business Performance of Small and Medium Enterprises in Malaysia: A Preliminary Analysis, International Journal of Business and Management Science, 3(2): 147-168, 2010.

[21] A. M. Pelham, and D.T. Wilson,"A longitudinal study of the impact of market structure, firm structure, strategy, and market orientation culture on dimensions of small-firm performance," Journal of the Academy of Marketing Science., 24(1): 27-43, 1996.

[22] Muslimin, S. Hadi, Ardiansyah, "The Relationship Between Logistics Performance and Financial Performance of SMEs in Indonesia, International Journal of Applied Business Economic Research, Vol. 13, No. 7. 4805-4814, 2015.

[23] H. Demsetz, "Industry structure, market rivalry, and public policy. Journal of Law and Economics, 16(1): 1-9, 1973.

[24] D.J, Bowersox, and P.J. Daugherty, "Logistics paradigms: The impact of information technology," Journal of Business Logistics, 16(1): 65-80, 1995. 